\title{
Resposta ao artigo "envelhecimento, finitude e morte: narrativas de idosos de uma unidade básica de saúde"
}

Reply to the article "aging, finitude and death: narratives of elderly people in a basic health unit" Respuesta al artículo "envejecimiento, initud y muerte: narrativas de ancianos en una unidad básica de salud"

Laura Naspolini', Murilo Henrique dos Santos $^{1 \oplus}$, Eliane Mazzuco dos Santos ${ }^{1 \oplus}$, Elonir Gomes ${ }^{1 \odot}$

${ }^{1}$ Universidade do Sul de Santa Catarina (UNISUL), Tubarão/SC

Caros autores,

"A morte é um excelente motivo para buscar um novo olhar para a vida":

A citação da médica Ana Claudia Quintana Arantes (2019)1 evidencia a importância desse tema não só para aceitarmos esse fato intrínseco ao ser humano, mas também para melhorarmos nossas relações com nós mesmos e com os outros. Desse modo, o artigo referido "Envelhecimento, finitude e morte: narrativas de idosos de uma unidade básica de saúde", ${ }^{2}$ ao trazer o relato de pessoas que estão mais próximas ao fim da vida, conduziu com maestria essa temática imprescindível, trazendo reflexões relevantes sobre a morte e o viver, abordadas em tópicos, como a diferença entre o envelhecer e o "ficar velho", o testamento vital, a relação dos idosos com a morte e a escolha do local de falecimento. Para tanto, a pesquisa foi realizada com 10 idosos que frequentavam uma clínica da família do Rio de Janeiro, sendo que os participantes possuíam 60 anos ou mais e eram considerados idosos ativos.

Isso posto, o estudo "Envelhecimento e morte: como os idosos encaram essa realidade?", ${ }^{3}$ que também traz como temática

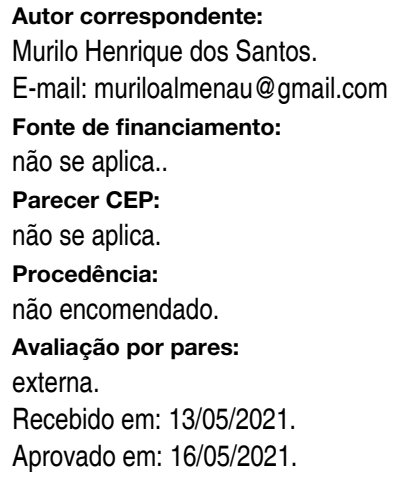


a percepção dos idosos sobre o envelhecer e o morrer, apresenta o medo do envelhecimento como algo subjetivo, intrinsecamente ligado à realidade que o indivíduo está inserido, evidenciando que o fator emocional e a qualidade de vida influenciam diretamente na relação do indivíduo com a morte. Nesse sentido, assim como no estudo citado, seria interessante que o vigente artigo demonstrasse se há uma relação entre a visão que o idoso possui da morte e o seu estilo de vida, para que, assim, houvesse uma melhor avaliação do perfil dos indivíduos que não se sentiram confortáveis em falar sobre a morte e quais falaram com tranquilidade. Além disso, deve-se salientar, como sugestão, a importância de se adicionar idosos não-saudáveis à entrevista, uma vez que, posteriormente, poderia ser feita uma comparação da visão sobre a morte que os idosos sadios e não-sadios possuem, avaliando se a presença de uma doença terminal, por exemplo, afeta a percepção do indivíduo sobre esse ato final da vida, como é constatado na obra de Arantes (2019):" "A morte é um dia que vale a pena viver". Acreditamos que isso enriqueceria, mais ainda, o artigo.

À medida que o artigo referido aborda a temática de envelhecimento, finitude e morte, há de se atentar ao contexto social ao qual o idoso está inserido. De fato, a insuficiência familiar na pessoa idosa, definida basicamente como baixo apoio social e vínculo familiar prejudicado, negligencia a experiência de maior benefício quando esse se encontrar doente ${ }^{4}$. A respeito de tal problemática, cenários caóticos, como o da atual pandemia de COVID-19, ratificam a urgência de se disseminar a discussão sobre os desejos de fim de vida, os quais podem ser discutidos com o médico, que deverá fazer constar em prontuário ${ }^{5}$. Dessa forma, a educação em saúde, proposta pelo artigo como um diálogo sobre o processo natural do morrer, uma vez efetivada, propicia a promoção de um ambiente que não apenas assegure ao idoso dignidade acerca dos desejos de fim de vida, mas também o acolha e corrobore o seu bem-estar social frente a um vínculo familiar prejudicado.

Portanto, instaurar discussões acerca do processo de envelhecer incita o debate sobre a finitude, bem como, a morte. O idoso, alvo principal dessa temática, está susceptível tanto a um contexto social e/ ou familiar fragilizado quanto às percepções diferentes frente ao processo saúde-doença. Estudos como o deste artigo fomentam, pois, a concretização da busca de um novo olhar para a vida.

\section{REFERÊNCIAS}

1. Arantes ACQ. A morte é um dia que vale a pena viver. Alfragide: Oficina do Livro; 2019.

2. Oliveira PID, Anderson MIP. Envelhecimento, finitude e morte: narrativas de idosos de uma unidade básica de saúde. Rev Bras Med Fam Comunidade. 2020;15(42):2195. DOI: https://doi.org/10.5712/rbmfc15(42)2195

3. Moura WCS, Trigueiro JVS, Lima EAR, Gois GAS, Torquato IMB, Silva PE. Envelhecimento e morte: como os idosos encaram essa realidade?. Rev Ciênc Saúde Nova Esperança.2012;10(1):12-9. DOI: https://revista.facene.com.br/index.php/revistane/article/view/395

4. Souza A, Pelegrini TS, Ribeiro JHM, Pereira DS, Mendes MA. Conceito de insuficiência familiar na pessoa idosa: análise crítica da literatura. Rev Bras Enferm [Internet]. 2015 Nov/Dez; [citado 2020 Set 30]; 68(6):1176-85. Disponível em: http://www.scielo.br/scielo. php?script=sci_arttext\&pid=S0034-71672015000601176\&lng=pt DOI: https://doi.org/10.1590/0034-7167.2015680625i

5. Verdi NC. A Covid-19 e a necessidade emergencial de se pensar sobre como se deseja o próprio fim. Longeviver.2020 Jul/Set;2(7):22-5. 